\section{Happy Birthday RöKo!}

Der Deutsche Röntgenkongress feiert sein 100. Jubiläum - feiern Sie mit! Seien Sie beim RöKo-Feier-Abend dabei und begehen Sie mit uns dieses besondere Ereignis.

\section{Donnerstag, 30. Mai 2019 - Glashalle CCL}

Es erwartet Sie eine Vielzahl von Attraktionen im Sinne der Goldenen 20iger, Spaß mit Fahrgeschäften, Karussells und Catering im Stil von Markt und Food-Festen. Lassen Sie sich überraschen! So werden Ihnen mit den DRESDNER SALON-DAMEN eine Sängerin, die auch Geige spielt begegnen, eine Akkordeon spielende Pianistin, eine Background singende Violinistin, eine Saxophon spielende Klarinettistin und eine Dame, die sowohl das Cello als auch den Kontrabass bedient.

Auch beteiligte Firmen werden Überraschungen einbringen und den Abend gemeinsam mit uns gestalten. Ein Abend ohne steife Struktur, aber mit viel Witz, Charme, Musik, einigen ereignisreichen Rückblicken sowie abwechslungsreichen Speisen, Getränken und süßen Verführungen.

Ab 21 Uhr übernimmt schließlich der Berliner DJ Sebastian Eis das Mischpult und präsentiert die besten Hits aus den letzten Jahrzehnten der Popmusik. Es darf ausgelassen getanzt werden! Wer es ruhiger angehen lassen möchte, kann den Abend aber auch an einer der Bars ausklingen lassen.

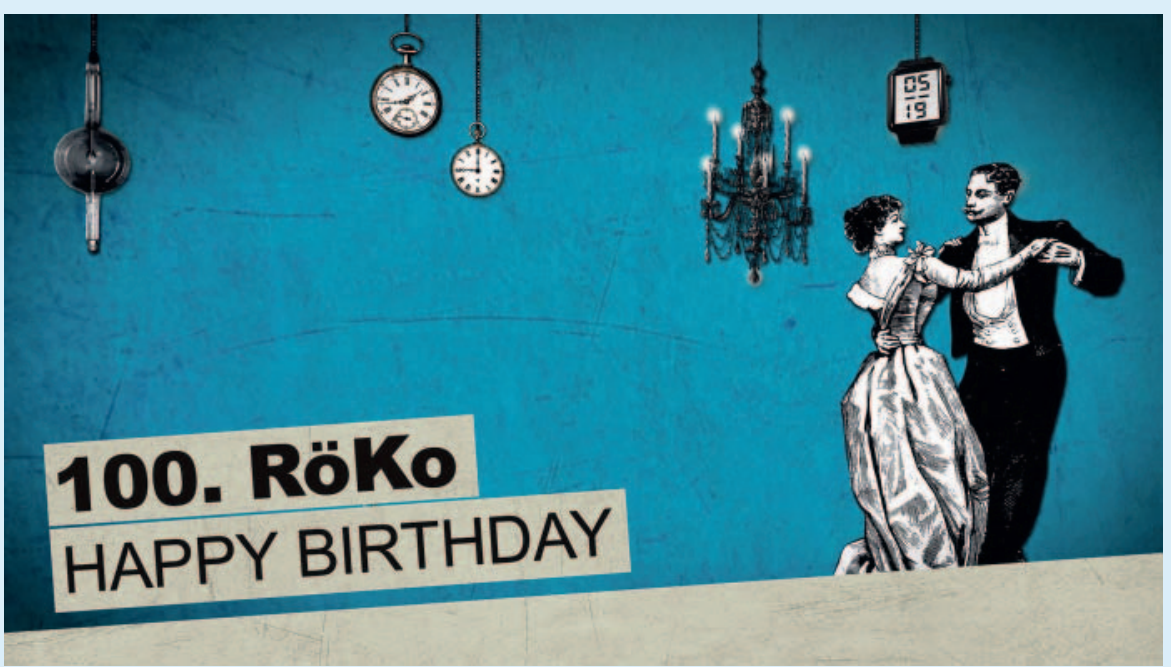

Tickets (inkl. Getränke, Speisen und Unterhaltungsprogramm) erhalten Sie unter der offiziellen Kongressanmeldung roentgenkongress.de > Anmeldung

Leitende und Niedergelassene, Oberärzte, Fachärzte, wissenschaftliche Angestellte, Physiker u. a. Naturwissenschaftler, Ingenieure/Angehörige der Industrie, Pensionäre/ Ehrenmitglieder $85,00 €$

Ärzte in Weiterbildung, MTRA $\quad 70,00 €$

Studierende, MTRA-Schüler/innen $\quad 40,00 €$ 